\title{
Targeting bladder cancer using activated $T$ cells armed with bispecific antibodies
}

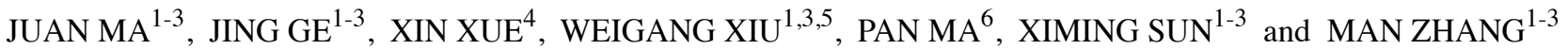 \\ ${ }^{1}$ Clinical Laboratory Medicine, Beijing Shijitan Hospital, Capital Medical University; ${ }^{2}$ Peking University Ninth School of \\ Clinical Medicine; ${ }^{3}$ Beijing Key Laboratory of Urinary Cellular Molecular Diagnostics, Beijing 100038 ; ${ }^{4}$ Department of \\ Immunology, China Basic Medical Theory of Chinese Medicine, Academy of Chinese Medical Sciences, Beijing 100700; \\ ${ }^{5}$ Department of Thoracic Oncology, Cancer Center and State Key Laboratory of Biotherapy, West China Hospital, \\ Sichuan University, Chengdu, Sichuan 610041; ${ }^{6}$ Key Laboratory of Protein and Peptide Pharmaceuticals, \\ Institute of Biophysics, Chinese Academy of Sciences, Beijing 100101, P.R. China
}

Received August 13, 2017; Accepted January 5, 2018

DOI: $10.3892 /$ or.2018.6211

\begin{abstract}
In the present study, we aimed to investigate whether EGFR or HER2 may serve as a target for T cellmediated immunotherapy against human bladder cancer. Expression of EGFR and HER2 was detected on the surface of bladder cancer cells, including Pumc-91 and T24 cells, and their chemotherapeutic drug-resistant counterparts. Activated $\mathrm{T}$ cells (ATCs) were generated from healthy PBMCs that were stimulated by the combination of anti-CD3 monoclonal antibody and anti-CD28 monoclonal antibody in the presence of interleukin-2 for 14 days. The ATCs were then armed with chemically hetero-conjugated anti-CD3xanti-EGFR (EGFRBi-Ab) or anti-CD3xanti-HER2 (HER2Bi-Ab). The specific cytolytic activity of ATCs armed with EGFRBi-Ab or HER2Bi-Ab against human bladder cancer cells was evaluated by lactate dehydrogenase activity assays in vitro. In contrast to unarmed ATCs, EGFRBi-Ab-armed ATCs and HER2BiAb-armed ATCs showed increased cytotoxic activity against bladder cancer cells. Moreover, Bi-Ab-armed ATCs expressed higher levels of activating marker CD69 and secreted more IFN- $\gamma$, TNF- $\alpha$ and IL- 2 than did unarmed ATCs. EGFRBi-Abor HER2Bi-Ab-armed ATCs may provide a promising immunotherapy for bladder cancer.
\end{abstract}

\section{Introduction}

Bladder cancer is one of the most frequent malignancies in the urinary tract, with an estimated 429,800 new cases and

Correspondence to: Dr Juan Ma or Professor Man Zhang, Clinical Laboratory Medicine, Beijing Shijitan Hospital, Capital Medical University, 10 Tieyi Road, Beijing 100038, P.R. China

E-mail: majuan96@sina.com

E-mail: zhangman@bjsjth.cn

Key words: bladder cancer, EGFR, HER2, immunotherapy, activated T cells
165,100 deaths occurring each year worldwide (1). The most common histologic type of bladder cancer in China, America and Europe is urothelial carcinoma (2). Although $~ 70 \%$ of urothelial carcinoma is diagnosed as non-muscle invasive with a favourable prognosis, $\sim 40 \%$ of these patients will progress to muscle invasive with a median survival of 15 months when metastatic disease develops (3). Metastatic disease is resistant to conventional cancer therapy, and the low cure rate in large part is due to development of multidrug resistance (4). Novel approaches such as immunotherapy are currently under investigation (5).

Human epidermal growth factor receptor (HER)1/EGFR and HER2 are implicated in the carcinogenesis of several malignancies $(6,7)$. They play critical roles in angiogenesis, cell growth, and survival signalling in bladder cancer, and their alterations are usually associated with poor prognosis $(8,9)$. Therapeutic antibodies and inhibitors of the EGFR or HER2 signalling pathway have shown encouraging results in the treatment of breast and colorectal cancer $(10,11)$. The success of anti-HER therapy in other cancers has led to its attempt in bladder cancer clinical trials; however, the benefits have not been fully achieved (12-15). Therefore, an alternative approach to improve the current strategy for bladder cancer is urgently needed.

One advancement is the use of bispecific antibodies (Bi-Abs), redirecting immune cells to tumour cells by having two different antigen binding sites, with one recognizing the tumour cells and the other recognizing the immune cells, usually $\mathrm{T}$ and NK cells. Researchers have engaged in taking advantage of immune cells to kill tumours for decades. Treatment of non-muscle-invasive bladder cancer with Bacillus Calmette-Guerin (BCG) demonstrated a remarkable reduction in recurrence by activating both the innate and adaptive immune systems (16). In 2016, and 2017, immunotherapy with programmed cell death 1/PD-1 ligand (PD-1/PD-L) immune checkpoint blockade to recover T-cell potency made a significant leap forward for patients with advanced or metastatic bladder cancer (17-19). Administration of Bi-Abs is also a strategy for enduring T-cell antitumour potency. Recently, phase I clinical trials with HER2Bi-Ab armed activated 
$\mathrm{T}$ cells (ATCs) have shown encouraging results in women with metastatic breast cancer and in men with metastatic castrate-resistant prostate cancer $(20,21)$.

In the present study, ATCs were armed with Bi-Abs to target bladder cancer cells and their chemotherapeutic drugresistant counterparts. Human bladder urothelial carcinoma cells were demonstrated to express high levels of EGFR and HER2 protein. A clinically approved anti-CD3 antibody was chemically conjugated with either an anti-EGFR or anti-HER2 antibodies. The anti-CD3xanti-EGFR bispecific antibody (EGFRBi-Ab) or anti-CD3xanti-HER2 bispecific antibody (HER2Bi-Ab) was then used to direct the ATCs to kill bladder cancer cells and their chemotherapeutic drug-resistant counterparts.

\section{Materials and methods}

Cell culture. The human bladder cancer cell line T24 was provided by the Chinese Academy of Sciences Culture Collection (Beijing). The drug-resistant bladder cancer cell line T24/DDP was established by stepwise exposure of T24 cells to escalating concentrations of cisplatin (Sigma-Aldrich, St. Louis, MO, USA), ranging from 0.01 to $0.60 \mu \mathrm{g} / \mathrm{ml}$ for $>6$ months $(22,23)$. The human bladder cancer cell line Pumc-91 was provided by the Cell Laboratory of Peking Union Medical College Hospital (Beijing). The drug-resistant cell line was Pumc-91/ADM, which was established by increasing the dosage of adriamycin gradually, and the final concentration of adriamycin was $1.0 \mu \mathrm{g} / \mathrm{ml}(23-26)$. The parental cell lines were cultured in RPMI-1640 medium supplemented with $10 \%$ heatinactivated foetal bovine serum (FBS), while drug-resistant cell lines were cultured in the above-mentioned medium with $18 \%$ FBS. Cells were incubated at $37^{\circ} \mathrm{C}$ in a standard $5 \% \mathrm{CO}_{2}$ cell incubator under a humidified atmosphere of $95 \%$ air. All agents for cell culture were purchased from Gibco Company (Gaithersburg, MD, USA).

Preparation of activated $T$ cells from peripheral blood lymphocytes (PBMCs). PBMCs were separated by Ficoll density gradient centrifugation from healthy donors supplied by Beijing Blood Bank. PBMCs were cultured at $1 \times 10^{6} / \mathrm{ml}$ in RPMI-1640 medium supplemented with $10 \%$ FBS and $300 \mathrm{ng} / \mathrm{ml}$ anti-CD3 monoclonal antibody (mAb) combined with $600 \mathrm{ng} / \mathrm{ml}$ anti-CD28 mAb (both from eBioscience, San Diego, CA, USA) in the presence of $100 \mathrm{IU} / \mathrm{ml}$ recombinant human IL-2 (PeproTech, Rocky Hill, NJ, USA). Fresh medium containing fresh interleukin- 2 was added every 2 or 3 days, and cells were cultured for 14 days and then cryopreserved. The study was performed according to the protocols approved by the Biomedical Research Ethics Committee of Beijing Shijitan Hospital of Capital Medical University.

Synthesis of anti-CD3xanti-EGFR (EGFRBi-Ab) and antiCD3xanti-HER2 (HER2Bi-Ab) bispecific antibodies and arming of ATCs. Anti-EGFR (Erbitux ${ }^{\circledR}$; Merck Serono, Darmstadt, Germany) or anti-HER2 (Herceptin ${ }^{\circledR}$; Roche, Indianapolis, IN, USA) was reacted with sulfo-SMCC, and anti-CD3 mAb (OKT3; eBioscience) was reacted with Traut's reagents using a previously described method (27-29). Cryopreserved ATCs were thawed, armed with EGFRBi-Ab or HER2Bi-Ab at a concentration of $50 \mathrm{ng} / 10^{6}$ cells at room temperature for $30 \mathrm{~min}$, and washed to eliminate unbound antibodies. ATCs preincubated with the combination of Erbitux $^{\circledast}\left(50 \mathrm{ng} / 10^{6}\right.$ cells), Herceptin ${ }^{\circledast}\left(50 \mathrm{ng} / 10^{6}\right.$ cells), and OKT3 (50 ng/10 cells) were used as control unarmed ATCs.

FlowJo cytometric analysis. To detect the expression of EGFR or HER2 on the cell surface, bladder cancer cells $\left(1 \times 10^{6}\right)$ were incubated for $30 \mathrm{~min}$ on ice with Erbitux ${ }^{\circledR}$ or Herceptin ${ }^{\circledR}$, followed by staining with anti-human-IgG-PE (BioLegend, San Diego, CA, USA). To detect EGFRBi-Ab or HER2Bi-Ab bound to bladder cancer cells, T24 cells were first incubated with EGFRBi-Ab or HER2Bi-Ab for $30 \mathrm{~min}$. The combination of Erbitux ${ }^{\circledR}$, Herceptin ${ }^{\circledR}$ with OKT3 was used as the negative control. Then,FITC-labelled goat anti-mouse IgG2a was used to detect the anti-CD3 moiety of the Bi-Ab. To examine the population of effector cells, ATCs were incubated with anti-human CD3-FITC, anti-human CD4-PE, anti-human CD8-APC and anti-human CD56-APC. To detect CD69 expression on ATCs, floating cells from T24 and ATC co-cultures were incubated with anti-human CD69-PE and anti-human CD3-FITC. The anti-human CD3-FITC, anti-human CD69-PE, anti-human CD4-PE, anti-human CD8-APC, anti-human CD56-APC, and anti-mouse IgG2a-PE secondary antibodies were from eBioscience. The cells were assayed with a Guava EasyCyte flow cytometer (Guava Technologies, Hayward, CA, USA), and data analysis was carried out with FlowJo Software Version 7.6.1 (Tree Star, Inc., Ashland, OR, USA).

In vitro cytotoxicity assay. Cytotoxicity assays were performed using a lactate dehydrogenase (LDH) activity assay kit (Sigma-Aldrich) according to the manufacturer's instructions, and real-time images were captured at a magnification of x200 with an optical microscope (Olympus, Tokyo, Japan). Target cells were seeded in triplicate in 96-well microplates at $1 \times 10^{4} /$ well before the addition of EGFRBi-Ab-armed,HER2Bi$\mathrm{Ab}$-armed or unarmed ATCs at the indicated effector-to-target ratio $(\mathrm{E} / \mathrm{T})$. Effector cells and tumour cells were allowed to interact at $37^{\circ} \mathrm{C}$ for $18 \mathrm{~h}$. Then, supernatants were collected, and LDH activity assays were performed to evaluate the death of target tumour cells at E/T ratios of 5:1 and 10:1.

ELISA assay. Target cells were seeded in triplicate in 96-well microplates at $1 \times 10^{4} /$ well before the addition of EGFRBi-Abarmed, HER2Bi-Ab-armed, or unarmed ATCs at E/T of 10:1. Effector cells and tumour cells were allowed to interact at $37^{\circ} \mathrm{C}$ for $18 \mathrm{~h}$. Then, supernatants were collected, and the production of IFN- $\gamma$, TNF- $\alpha$ and IL-2 was quantified with a human cytokine ELISA kit (eBioscience) according to the manufacturer's instructions.

Statistical analyses and reproducibility. All experiments were repeated three times. Data were analysed using GraphPad Prism 5 software and are presented as the mean \pm SD. Unpaired Student's t-test (two-tailed) or the Mann-Whitney test was used for comparison of two groups where appropriate. One-way analysis of variance (ANOVA) followed by Dunnett's post hoc test was used for multiple comparisons. $\mathrm{P}<0.05$ was considered statistically significant. Numbers with a significant difference from a control are denoted by an asterisk in the figures. 
A

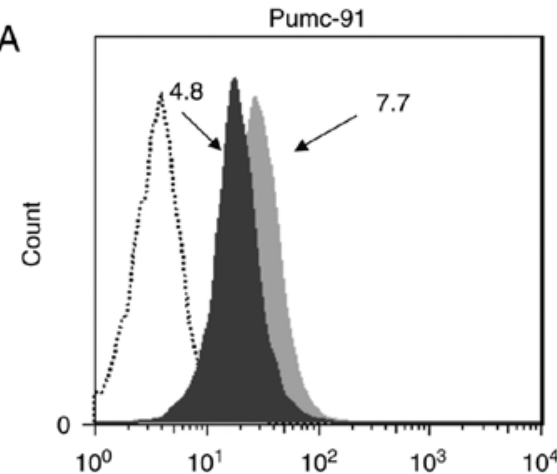

B

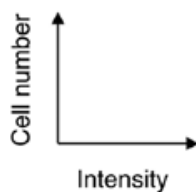

Pumc-91/ADM

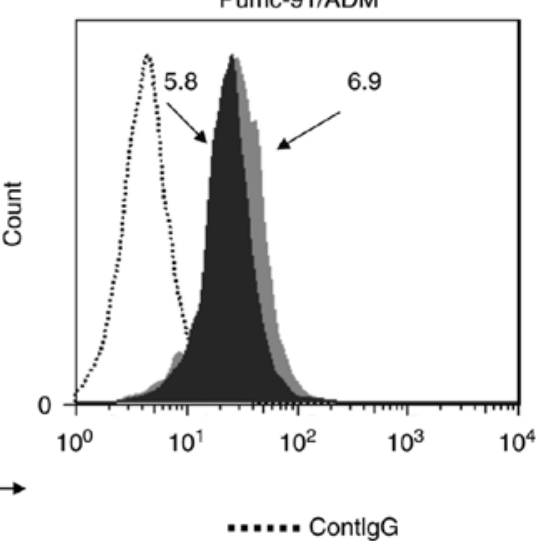

C

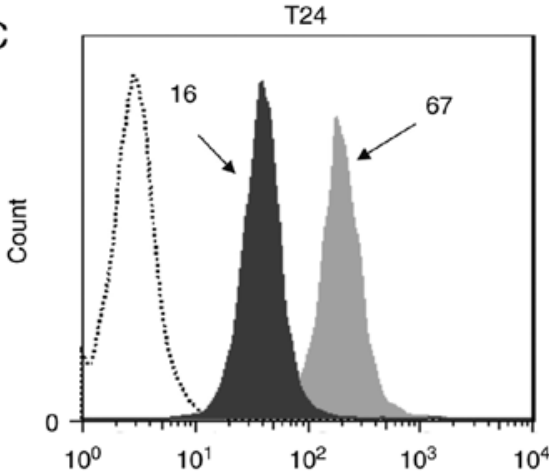

D

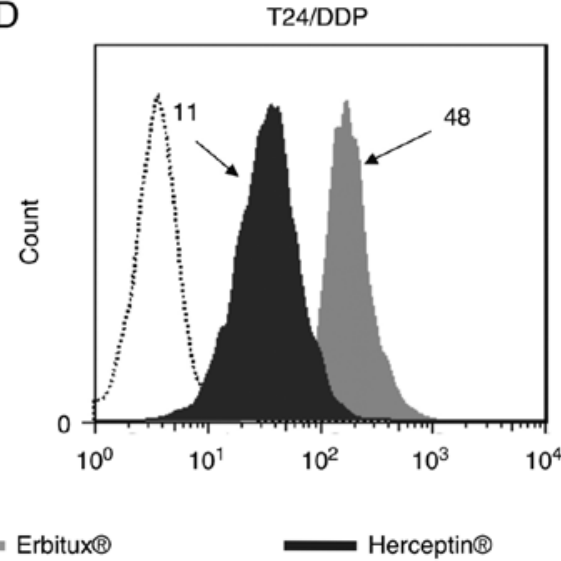

Figure 1. Expression of EGFR and HER2 on human bladder cancer cells and their chemotherapeutic drug-resistant counterparts. Surface expression of EGFR or HER2 was evaluated by flow cytometry on human bladder cancer cells Pumc-91 and T24 and their respective chemotherapeutic drug-resistant counterparts Pumc-91/ADM and T24/DDP. Shaded histograms represent cells stained with Erbitux ${ }^{\circledast}$ (light grey) or Herceptin ${ }^{\circledR}$ (dark grey), and open histograms represent

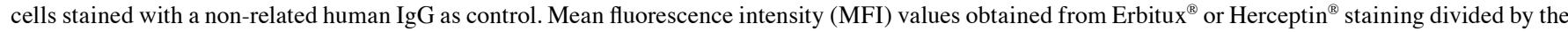
control human $\mathrm{IgG}$ staining are indicated. A representative experiment is shown from the three experiments.

\section{Results}

Confirmation of EGFR and HER2 expression on human bladder cancer cells. The surface expression of EGFR and HER2 on human muscle-invasive bladder cancer cells, including Pumc-91 and T24 cells, and their chemotherapeutic drug-resistant counterparts, Pumc-91/ADM and T24/DDP, were assessed by flow cytometry. The drug-resistant characteristics of Pumc-91/ADM and T24/DDP were confirmed by MTT assay, reverse transcription polymerase chain reaction and flow cytometry in our previous studies (22-25). As shown in Fig. 1, mean fluorescence intensity (MFI) values obtained from humanized anti-human EGFR Ab (Erbitux $\left.{ }^{\circledR}\right)$ or anti-human HER2Ab (Herceptin ${ }^{\circledR}$ ) staining divided by control antibody staining are indicated, and high expression of EGFR and HER2 was detected in all human bladder cancer cells.

Preparation and characterization of EGFRBi-Ab, HER $2 B i-A b$ and ATCs. We next constructed two types of bispecific antibodies that recognized both CD3 on T cells and EGFR or HER2 on bladder cancer cells. Erbitux ${ }^{\circledR}$ or Herceptin ${ }^{\circledR}$ antibody was chemically hetero-conjugated to OKT3 and named EGFRBi-Ab or HER2Bi-Ab (27-29). The binding specificity of EGFRBi-Ab and HER2Bi-Ab was tested against EGFR and HER2, respectively. T24 bladder cancer cells were stained with EGFRBi-Ab or HER2Bi-Ab, and then an antimouse-IgG2a-FITC was added to detect the CD3 moiety of the Bi-Abs. Only functional bispecific antibody was able to bind to T24 cells and be detected through mouse origin OKT3 by anti-mouse $\operatorname{IgG} 2$ a secondary antibody. In the control where Erbitux ${ }^{\circledR}$, Herceptin ${ }^{\circledR}$ and OKT3 were used without conjugation, Erbitux ${ }^{\circledR}$ and Herceptin ${ }^{\circledR}$ were able to bind to T24 cells but could not be recognized by the anti-mouse IgG2a secondary antibody. As shown in Fig. 2A, positively stained cells were detected in $>95 \%$ of the T24 population with a MFI of 7.38 or 4.03 for EGFRBi-Ab or HER2Bi-Ab staining, respectively. The scheme for flow cytometry-based binding assays for EGFRBi-Ab and HER2Bi-Ab is demonstrated in Fig. 2B. Moreover, evaluation of the binding of $\mathrm{Bi}-\mathrm{Ab}$ to $\mathrm{CD}^{+}$ cells has been previously shown by a similar method (27-29).

To produce a sufficient number of effector cells, PBMCs from buffy coat were stimulated by the combination of ant-CD3 $\mathrm{mAb}$ with anti-CD28 mAb in the presence of IL-2 for 14 days as described in Materials and methods, then the effector cells were quantitatively analysed by FACS. As shown in Fig. 2C-E, the cell population contained almost $95-96 \% \mathrm{CD}^{+}$cells among which there were $\sim 63.2 \% \mathrm{CD}^{+} \mathrm{CD}^{+}$(Fig. $2 \mathrm{C}$ ) and $30.3 \% \mathrm{CD}^{+} \mathrm{CD}^{+}$cells (Fig. 2D). Regarding the $\mathrm{CD}^{-}$population, most of them were CD56-positive (Fig. 2E). Overall, these data suggested that the effector cells were mainly composed of ATCs and a small population of NK cells.

Activation of EGFRBi-Ab-or HER2Bi-Ab-armed ATCs by human bladder cancer cells. Based on our previous 

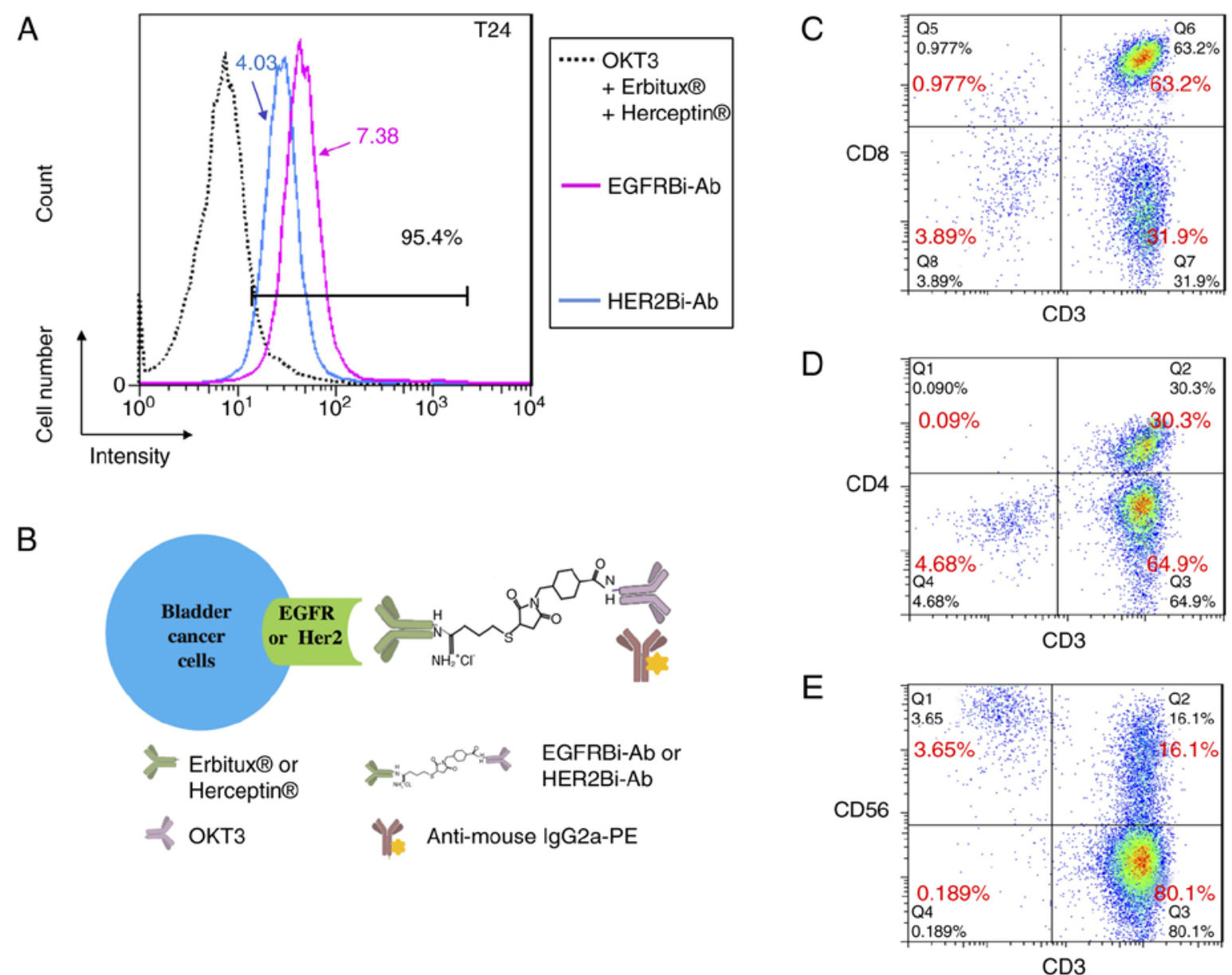

Figure 2. General scheme for the generation of anti-CD3xanti-EGFR and anti-CD3xanti-HER2 bispecific antibodies and analysis of activated T cells. (A) Flow cytometry-based binding assay for EGFRBi-Ab and HER2Bi-Ab. Bladder cancer cell line T24 was incubated with EGFRBi-Ab (0.5 $\mu \mathrm{g} / \mathrm{ml}$, pink histogram), HER2Bi-Ab $\left(0.5 \mu \mathrm{g} / \mathrm{ml}\right.$, blue histogram) or a mixture of OKT3, Erbitux ${ }^{\circledast}$ and Herceptin ${ }^{\circledast}(0.5 \mu \mathrm{g} / \mathrm{ml}$, black histogram), and Bi-Ab binding was examined by detecting the anti-CD3 moiety of the Bi-Ab with PE-labelled anti-mouse IgG2a. (B) The scheme for flow cytometry-based binding assays for EGFRBi-Ab and HER2Bi-Ab. (C-E) Flow cytometric analysis of cell-specific surface molecule expression on activated $\mathrm{T}$ cells. A representative experiment from the three experiments is shown.

experiments (27-29), we chose $50 \mathrm{ng} / 10^{6}$ cells as the concentration of EGFRBi-Ab or HER2Bi-Ab with which to arm ATCs for all subsequent experiments, and ATCs mixed with individual OKT3, Erbitux ${ }^{\circledast}$ and Herceptin ${ }^{\circledast}$ were used as unarmed control ATCs. The antitumour effects of EGFRBi-Ab- or HER2Bi-Ab-armed ATCs on T24 cells were tested at an effector/target (E/T) ratio of 10:1. After $18 \mathrm{~h}$ of incubation of T24 cells with EGFRBi-Ab-armed ATCs or HER2Bi-Ab-armed ATCs, FACS analysis showed increased expression of CD69, an activation marker for T cells, in $\mathrm{Bi}-\mathrm{Ab}$-armed ATCs compared with that in their unarmedATC counterparts (Fig. 3A). As shown in Fig. 3B, real-time images demonstrated that both EGFRBi-Ab-armed ATCs and HER2Bi-Ab-armed ATCs, but not unarmed control ATCs aggregated with T24 cells in culture, clustering around the edge of target cell bulk, which showed specific activation of EGFRBi-Ab- or HER2Bi-Ab-armed ATCs.

Cytotoxic effects of EGFRBi-Ab-or HER2Bi-Ab-armed ATCs on human bladder cancer cells. EGFRBi-Ab- or HER2Bi-Abarmed ATCs were tested for cytotoxicity on Pumc-91, T24, Pumc-91/ADM and T24/DDP human bladder cancer cells. Lactate dehydrogenase (LDH) activity assays were performed to evaluate the death of target bladder cancer cells at E/T ratios of 5:1 and 10:1. As shown in Fig. 4, after an 18-h incubation with EGFRBi-Ab-armed ATCs or HER2Bi-Ab-armed ATCs, the concentration of LDH with armed effectors was significantly greater than that with unarmed effectors in all the bladder cancer cells, indicating the specific cytotoxicity of EGFRBi-Ab- or HER2Bi-Ab-armed ATCs on these cells.

Cytotoxic effects of EGFRBi-Ab-or HER2Bi-Ab-armed ATCs on human bladder cancer cells with cytokine production. To analyse the levels of $\mathrm{T}$ cell-derived cytokines involved in cytotoxicity, cell supernatants were analysed for IFN- $\gamma$, TNF- $\alpha$ and IL-2 production at E/T ratio of 10:1. As shown in Fig. 5, significantly more IFN- $\gamma$ (Fig. 5A), TNF- $\alpha$ (Fig. 5B) and IL-2 (Fig. 5C) secretion was observed from EGFRBi-Ab- or HER2Bi-Ab-armed ATCs than from their unarmed control ATC counterparts when ATCs were co-cultured with Pumc-91, T24, Pumc-91/ADM or T24/DDP.

\section{Discussion}

Due to development of multidrug resistance, metastases of bladder cancer are resistant to conventional cancer therapy. 
A

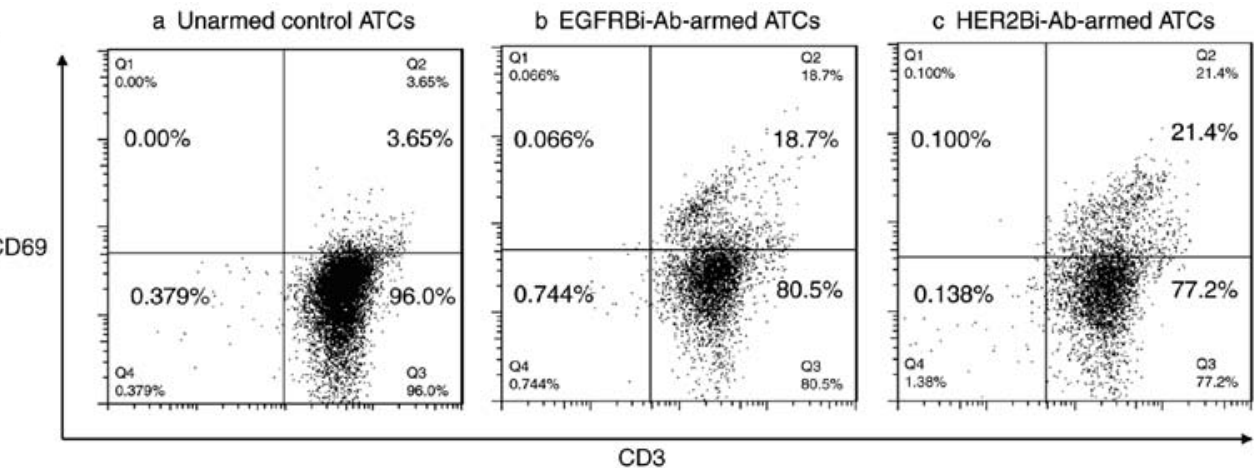

B

a Unarmed control ATCs

b EGFRBi-Ab-armed ATCs

c HER2Bi-Ab-armed ATCs
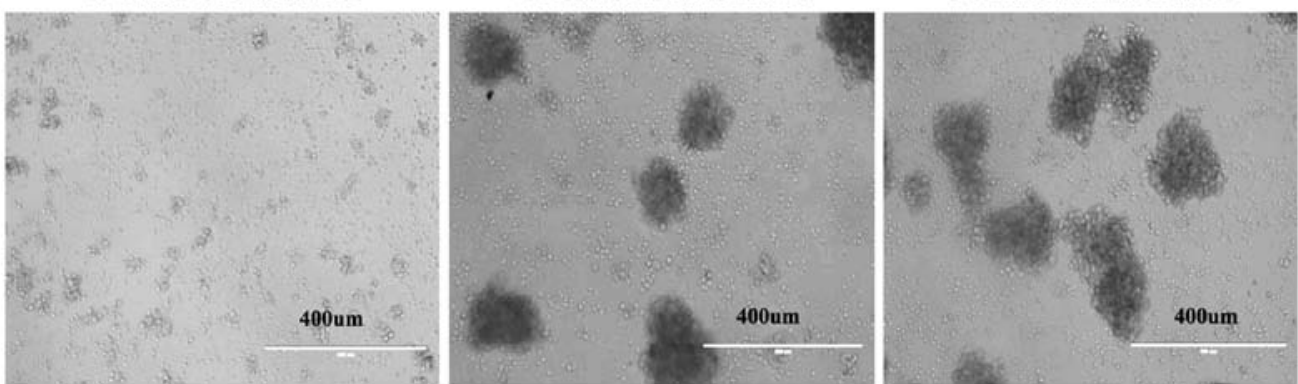

Figure 3. T cell activation of EGFRBi-Ab- or HER2Bi-Ab-armed ATCs by bladder cancer cells. T24 target cells (1x10 $/$ well) were incubated with either EGFRBi-Ab-armed ATCs (50 ng/EGFRBi-Ab/106 ATCs) or HER2Bi-Ab-armed ATCs (50 ng/HER2Bi-Ab/10 ${ }^{6} \mathrm{ATCs}$ ) for $18 \mathrm{~h}$ at effector/target (E/T) ratio of 10:1 in a 96-well microplate. The combination of OKT3, Erbitux ${ }^{\circledR}$ and Herceptin ${ }^{\circledR}$ with ATCs served as unarmed control ATCs. (A) Expression of CD69 on EGFRBi-Ab-armed ATCs or HER2Bi-Ab-armed ATCs was detected by flow cytometry. (B) Real-time images were captured at x200 magnification. T24 cells were incubated with: a, unarmed control ATCs; b, EGFRBi-Ab-armed ATCs; c, HER2Bi-Ab-armed ATCs. A representative experiment from the three experiments is shown.
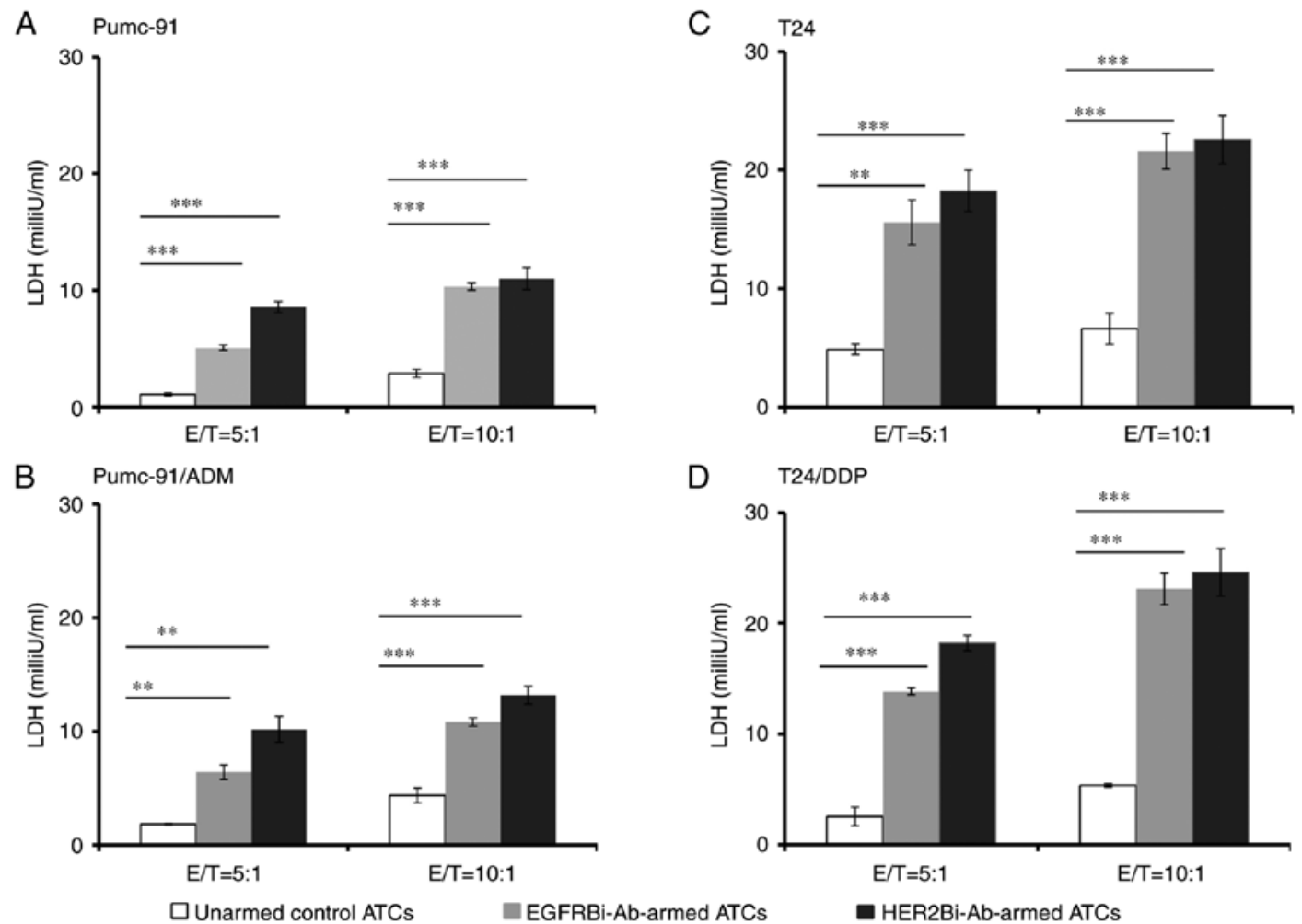

口Unarmed control ATCs

EGFRBi-Ab-armed ATCs

- HER2Bi-Ab-armed ATCs

Figure 4.Cytotoxic effects of EGFRBi-Ab- or HER2Bi-Ab-armed ATCs against bladder cancer cells. Target cells (Pumc-91,Pumc-91/ADM,T24 and T24/DDP, $1 \times 10^{4} /$ well) were incubated with either EGFRBi-Ab-armed ATCs (50 ng/EFGRBi-Ab/10 ${ }^{6} \mathrm{ATCs}$ ) or HER2Bi-Ab-armed ATCs (50 ng/HER2Bi-Ab/10 ${ }^{6} \mathrm{ATCs}$ ) in 96-well microplates. Lactate dehydrogenase (LDH) activity assays were performed with EGFRBi-Ab- or HER2Bi-Ab-armed ATCs against human bladder cancer cells. Supernatant of co-cultures at an E/T ratio of 5:1 or 10:1 was harvested at $18 \mathrm{~h}$, and an LDH activity assay was performed to determine cytotoxicity against Pumc-91 and T24 cells (A and C) and their chemotherapeutic drug-resistant counterparts Pumc-91/ADM and T24/DDP (B and D), respectively. ATCs with the combination of OKT3, Erbitux ${ }^{\circledast}$ and Herceptin ${ }^{\circledR}$ were named unarmed control ATCs. The data are mean \pm SD of triplicate determination. A representative experiment from the three experiments is shown. ${ }^{* *} \mathrm{P}<0.01,{ }^{* * *} \mathrm{P}<0.001$, EGFRBi-Ab- or HER2BiAb-armed ATCs compared with unarmed control ATCs under similar conditions. 
A

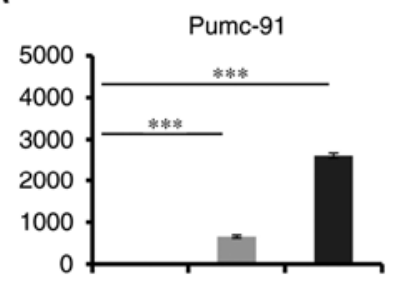

B

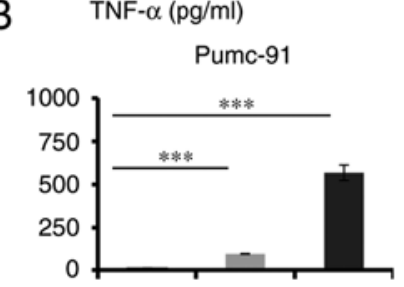

C

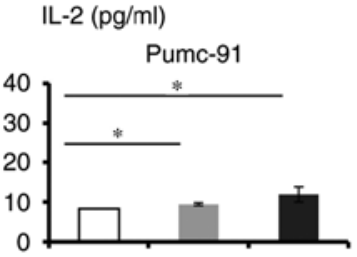

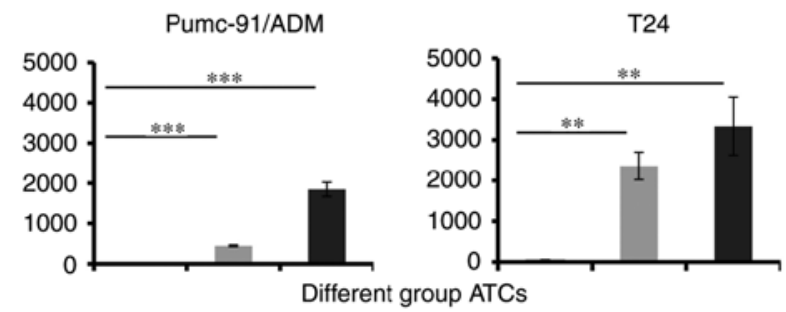
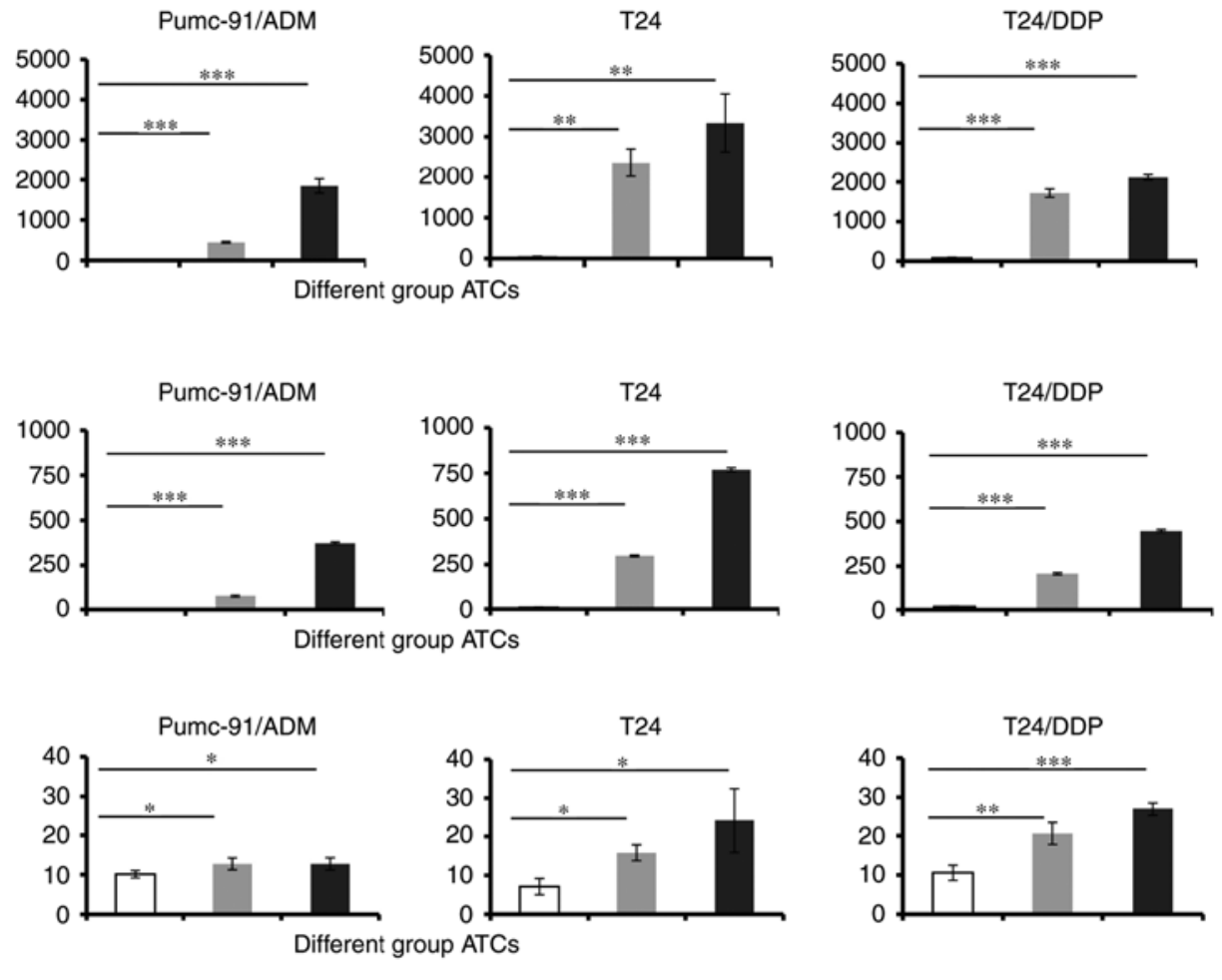

$\square$ Unarmed control ATCs

EGFRBi-Ab-armed ATCs

- HER2Bi-Ab-armed ATCs

Figure 5. (A) IFN- $\gamma$, (B) TNF- $\alpha$ and (C) IL-2 secretion by EGFRBi-Ab- or HER2Bi-Ab-armed ATCs against bladder cancer cells. Target cells (Pumc-91, Pumc-91/ADM, T24 and T24/DDP, 1x10 /well) were incubated with either EGFRBi-Ab-armed ATCs (50 ng/EGFRBi-Ab/106 ATCs) or HER2Bi-Ab-armed ATCs (50 ng/HER2Bi-Ab/10 ${ }^{6}$ ATCs) in 96-well microplates. Supernatant of co-cultures at E/T of 10:1 was harvested at 18 h and analysed using a specific ELISA kit for cytokine production against Pumc-91 and T24 cells (A and C) and their chemotherapeutic drug-resistant counterparts Pumc-91/ADM and T24/DDP (B and D), respectively. ATCs with the combination of OKT3, Erbitux ${ }^{\circledR}$ and Herceptin ${ }^{\circledR}$ were named as unarmed control ATCs. The data are mean $\pm \mathrm{SD}$ of triplicate determination. A representative experiment from the three experiments is shown. ${ }^{*} \mathrm{P}<0.05,{ }^{* *} \mathrm{P}<0.01,{ }^{* * *} \mathrm{P}<0.001, \mathrm{EGFRBi}-\mathrm{Ab}-\mathrm{or}$ HER2Bi-Ab-armed ATCs compared with unarmed control ATCs under similar conditions.

As large numbers of activated $\mathrm{T}$ cells can be produced ex vivo, and as mAbs specific for a tumour surface protein have become available, $\mathrm{Bi}-\mathrm{Abs}$ have shown encouraging antitumour effects in both experimental and clinical studies in recent years $(20,21,27-32)$. Bi-Abs, usually comprising an anti-CD3 mAb hetero-conjugated to a different $\mathrm{mAb}$ specific to a selected tumour-associated antigen (TAA), will empower each TAA-specific T cell to retarget tumour cells. HER 2 and EGFR are ideal targets in antibody-based therapeutic strategies for tumours especially breast and colorectal cancer $(10,11)$. Therefore, targeting HER2 or EGFR appears to be a reasonable way to treat bladder cancer.

In the present study, we examined the expression of EGFR and HER2 on human muscle-invasive bladder cancer cells and their chemotherapeutic drug-resistant counterparts. Co-expression of HER2 and EFGR, which suggests activation of both the AKT/PTEN/mTOR and RAS/MEK/ERK pathways, has been reported with worse prognosis in several types of cancer, including bladder cancer $(8,33)$. Synergy among different signaling pathways is essential for more aggressive disease and therefore deserves further consideration. We further tested whether EGFR or HER2 is a useful target for the development of a Bi-Ab therapy in bladder cancer, and evaluated the antitumour effects of Bi-Ab-armed ATCs. In vitro cytotoxicity assays demonstrated that EGFRBi-Abarmed or HER2Bi-Ab-armed ATCs displayed significant cytotoxic activity against bladder cancer cells, whereas neither the anti-EGFR antibody nor the anti-HER 2 antibody alone had an inhibitory effect on them (data not shown). Moreover, our investigation showed that Bi-Ab-armed ATCs expressed higher levels of activating marker CD69 and secreted more IFN- $\gamma$, TNF- $\alpha$ and IL- 2 than did unarmed ATCs.

The present study demonstrated that compared with control unarmed ATCs, those armed with either EGFRBi-Ab or HER2Bi-Ab released high levels of $\mathrm{LDH}$, indicating that armed ATCs mediated specific cytotoxicity against bladder cancer cells. These results showed that T-cell cytotoxicity was dependent upon the engagement of EGFR or HER2 via $\mathrm{Bi}-\mathrm{Ab}$ linkage. Indeed, at the $\mathrm{E} / \mathrm{T}$ ratio of 10:1, $50 \mathrm{ng} \mathrm{Bi}-\mathrm{Ab}$ per $10^{6}$ ATCs showed remarkable LDH release against tumour cells after an 18-h incubation, whereas anti-EGFR/anti-HER2 antibody had no inhibitory effect at the concentration of $10 \mu \mathrm{g} / \mathrm{ml}$ after a 72-h incubation (data not shown). Moreover, the present study supported that arming ATCs with Bi-Abs circumvented the requirement for major histocompatibility complex antigen recognition by ATCs. HER2Bi-Ab-armed ATCs could not kill CD3'HER2- K562 cells, demonstrating the specificity of the HER2Bi-Ab $(28,29)$. Moreover, effector cells armed with EGFRBi-Ab, but not with HER2Bi-Ab could kill EGFR ${ }^{+}$HER2- U87-MG cells (27).

Our results showed that ATCs armed with either EGFRBi-Ab or HER2Bi-Ab released high levels of IFN- $\gamma$, 
TNF- $\alpha$ and IL-2 upon incubation with bladder cancer cells. The increased cytokine secretion indicated that the ATCs were reactivated when encountering tumour cells. IFN- $\gamma$ and TNF- $\alpha$ secreted by Bi-Ab-armed ATCs are directly tumouricidal and can also activate endogenous immune cells in vivo, counteracting tumour-derived suppression. Moreover, based on flow cytometry assays, both HER2Bi-Ab-armed ATCs and EGFRBi-Ab-armed ATCs expressed higher levels of CD69 than unarmed-ATC counterparts. CD69, a marker of early T-cell activation, acts as a costimulatory molecule enhancing T-cell responses following TCR-ligand interaction (34). Our real-time images also revealed that armed ATCs but not unarmed control ATCs aggregated with bladder cancer cells in culture, clustering around the edge of the target cell bulk, indicating the specific activation of EGFRBi-Ab- or HER2BiAb-armed ATCs. In several phase I clinical trials, patients infused with HER2Bi-Ab-armed ATCs exhibited elevated levels of cytokines in their serum, suggesting that armed ATC administration stimulated the endogenous immunity to develop antitumour activity $(20,21)$.

In conclusion, both EGFR and HER2 appear to be suitable targets for $\mathrm{T}$ cell-mediated immunotherapy against bladder cancer including chemotherapeutic drug-resistant bladder cancer. EGFRBi-Ab- or HER2Bi-Ab-armed ATCs may provide a promising approach for bladder cancer in the future.

\section{Acknowledgements}

The present study was funded by grants from the National Nature Science Foundation of China (no. 31400754), Beijing Key Laboratory of Urinary Cellular Molecular Diagnostics (Z151100001615060), Beijing Natural Science Foundation (no. 7172106), Beijing Municipal Administration of Hospitals' Ascent Plan (DFL20150701) and Beijing Shijitan Hospital Foundation (2015C-12).

\section{Competing interests}

The authors declare that they have no competing interests.

\section{References}

1. Torre LA, Bray F, Siegel RL, Ferlay J, Lortet-Tieulent J and Jemal A: Global cancer statistics, 2012. CA Cancer J Clin 65: 87-108, 2015.

2. Pang $\mathrm{C}$, Guan $\mathrm{Y}, \mathrm{Li} \mathrm{H}$, Chen $\mathrm{W}$ and Zhu G: Urologic cancer in China. Jpn J Clin Oncol 46: 497-501, 2016.

3. Von der Maase H, Sengelov L, Roberts JT, Ricci S, Dogliotti L, Oliver T, Moore MJ, Zimmermann A and Arning M: Long-term survival results of a randomized trial comparing gemcitabine plus cisplatin, with methotrexate, vinblastine, doxorubicin, plus cisplatin in patients with bladder cancer. J Clin Oncol 23: 4602-4608, 2005.

4. Krishna R and Mayer LD: Multidrug resistance (MDR) in cancer. Mechanisms, reversal using modulators of MDR and the role of MDR modulators in influencing the pharmacokinetics of anticancer drugs. Eur J Pharm Sci 11: 265-283, 2000.

5. Carneiro BA, Meeks JJ, Kuzel TM, Scaranti M, Abdulkadir SA and Giles FJ: Emerging therapeutic targets in bladder cancer. Cancer Treat Rev 41: 170-178, 2015.

6. Appert-Collin A, Hubert P, Crémel G and Bennasroune A: Role of ErbB receptor in cancer cell migration and invasion. Front Pharmacolo 6: 283, 2015.

7. Smolensky D, Rathore K and Cekanova M: Molecular targets in urothelialcancer: Detection, treatment, and animal models ofbladder cancer. Drug Des Devel Ther 10: 3305-3322, 2016.
8. Koletsas N, Koletsa T, Choidas S, Anaqnostopoulos K, Touloupidis S, Zaramboukas T, Raptou G, Papadopoulos N and Lambropoulou M: Immunohistochemical investigation of HER/AKT/mTOR pathway and cellular adhesion molecules in urothelial carcinomas. Patholog Res Int 2017: 6794150, 2017.

9. Zhao J, Xu W, Zhang Z, Song R, Zeng S, Sun Y and Xu C: Prognostic role of HER2 expression in bladder cancer: A systematic review and meta-analysis. Int Urol Nephrol 47: 87-94, 2015.

10. Ross JS, Slodkowska EA, Symmans WF, Pusztai L, Ravdin PM and Hortobagyi GN: The HER-2 receptor and breast cancer: Ten years of targeted anti-HER-2 therapy and personalized medicine. Oncologist 14: 320-368, 2009.

11. Lo Nigro C, Ricci V, Vivenza D, Granetto C, Fabozzi T, Miraqlio E and Merlano MC: Prognostic and predictive biomarkers in metastatic colorectal canceranti-EGFR therapy. World J Gastroenterol 22: 6944-6954, 2016.

12. Hussain M, Daignault S, Agarwal N, Grivas PD, SiefkerRadtke AO, Puzanov I, MacVicar GR, Levine EG, Srinivas S, Twardowski P, et al: A randomized phase 2 trial of gemcitabine/cisplatin with or without cetuximab in patients with advanced urothelial carcinoma. Cancer 120: 2684-2693, 2014.

13. Philips GK, Halabi S, Sanford BL, Bajorin D and Small EJ; Cancer and Leukaemia Group B: A phase II trial of cisplatin, fixed dose-rate gemcitabine and gefitinib for advanced urothelial tract carcinoma: Results of the Cancer and Leukaemia Group B 90102. BJU Int 101: 20-25, 2008.

14. Oudard S, Culine S, Vano Y, Goldwasser F, Théodore C, Nguyen T, Voog E, Banu E, Vieillefond A, Priou F, et al: Multicentre randomized phase II trial of gemcitabine + platinum, with or without trastuzumab, in advanced or metastatic urothelial carcinoma overexpressing Her2. Eur J Cancer 51: 45-54, 2015.

15. Powles T, Huddart RA, Elliott T, Sarker SJ, Ackerman C, Jones R, Hussain S, Crabb S, Jagdev S, Chester J, et al: Phase III, doubled-blind, randomized trial that compared maintenance lapatinib versus placebo after first-line chemotherapy in patients with human epidermal growth factor receptor $1 / 2$-positive metastatic bladder cancer. J Clin Oncol 35: 48-55, 2017.

16. Wu Y, Enting D, Rudman S and Chowdhury S: Immunotherapy for urothelial cancer: From BCG to checkpoint inhibitors and beyond. Expert Rev Anticancer Ther 15: 509-523, 2015.

17. Rosenberg JE, Hoffman-Censits J, Powles T, van der Heijden MS, Balar AV, Necchi A, Dawson N, O'Donnell PH, Balmanoukian A, Loriot Y, et al: Atezolizumab in patients with locally advanced and metastatic urothelial carcinoma who have progressed following treatment with platinum-based chemotherapy: A single-arm, multicentre, phase 2 trial. Lancet 387: 1909-1920, 2016.

18. Sharma P, Callahan MK, Bono P, Kim J, Spiliopoulou P, Calvo E, Pillai RN, Ott PA, de Braud F, Morse M, et al: Nivolumab monotherapy in recurrent metastatic urothelial carcinoma (CheckMate 032): A multicentre, open-label, two-stage, multiarm, phase 1/2 trial. Lancet Oncol 17: 1590-1598, 2016.

19. Bellmunt J, De Wit R, Vaughn DJ, Fradet Y, Lee JL, Fong L, Vogelzang NJ, Climent MA, Petrylak DP, Choueiri TK, et al: Pembrolizumab as second-line therapy for advanced urothelial carcioma. N Eng J Med 376: 1015-1026, 2017.

20. Lum LG, Thakur A, Al-Kadhimi Z, Colvin GA, Cummings FJ, Legare RD, Dizon DS, Kouttab N, Maizei A, Colaiace W, et al: Targeted T-cell therapy in stage IV breast cancer: A phase I clinical trial. Clin Cancer Res 21: 2305-2314, 2015.

21. Vaishampayan U, Thakur A, Rathore R, Kouttab N and Lum LG: Phase I study of anti-CD3 $x$ anti-Her2 bispecific antibody in metastatic castrate resistant prostate cancer patients. Prostate Cancer 2015: 285193, 2015

22. Zhao M, Zhang M and Ma P: Establishment of cisplatin-multi drug resistance cell line of human bladder cancer T24 and its biological characteristics. Immun Clin Med 22: 338-341, 2015 (In Chinese).

23. Wang S, Lei T and Zhang M: The reversal effect and its mechanisms of tetramethylpyrazine on multidrug resistance in human bladder cancer. PLoS One 11: e0157759, 2016.

24. Zhang M, Jin S and Zhang M: The establishment and biological characteristics evaluation of human multidrug-resistant bladder cancer Pumc-91/ADM cell line. J Med Res 38: 70-72, 2009 (In Chinese).

25. Wang S, Meng Q, Xie Qi and Zhang M: Effect and mechanism of resveratrol on drug resistance in human bladder cancer cells. Mol Med Rep 15: 1179-1187, 2017.

26. Xiu W, Ma J, Lei T, Zhang M and Zhou S: Immunosuppressive effect of bladder cancer on function of dendritic cells involving of Jak2/STAT3 pathway. Oncotarget 7: 63204-63214, 2016. 
27. Ma P, He Q, Li W, Li X, Han H, Jin M, Liu C, Tao H, Ma J and Gao B: Anti-CD3 x EGFR bispecific antibody redirects cytokine-induced killer cells to glioblastoma in vitro and in vivo. Oncol Rep 34: 2567-2575, 2015.

28. Han H, Ma J, Zhang K, Li W, liu C, Zhang Y, Zhang G, Ma P, Wang L, Zhang G, et al: Bispecific anti-CD3 x anti-HER2 antibody mediates $\mathrm{T}$ cell cytolytic activity to HER2-positive colorectal cancer in vitro and in vivo. Int J Oncol 45: 2446-2454, 2014.

29. Ma J, Han H, Liu D, Li W, Feng H, Xue X, Wu X, Niu G, Zhang G Zhao Y, et al: HER2 as a promising target for cytotoxicity T cells in human melanoma therapy. PLoS One 8: e73261, 2013.

30. Ma J, Ma P, Zhao C, Xue X, Han H, Liu C, Tao H, Xiu W, Cai J and Zhang M: B7-H3 as a promising target for cytotoxicity T cell in human cancer therapy. Oncotarget 7: 29480-29491, 2016.
31. Lum LG and Thakur A: Targeting T cells with bispecific antibodies for cancer therapy. BioDrugs 25: 365-379, 2011.

32. Bhutani D and Lum LG: Activated T cells armed with bispecific antibodies killtumor targets. Curr Opin Hematol 22: 476-483, 2015.

33. Friedman M, Lindström S, Ekerljumg L, Andersson-Svahn H, Carlsson J, Brismar H, Gedda L, Frejd FY and Ståhl S: Engineering and characterization of a bispecific HER $2 \times$ EGFRbinding affibody molecule. Biotechnol Appl. Biochem 54: 121-131, 2009.

34. Sathaliyawala T, Kubota M, Yudanin N, Turner D, Camp P, Thome JJ, Bickham KL, Lerner H, Goldstein M, Sykes M, et al: Distribution and compartmentalization of human circulating and tissue-resident memory T cell subsets. Immunity 38: 187-197, 2013. 